\title{
Produção e Características do Efluente e Composição Bromatológica da Silagem de Capim-Elefante Contendo Diferentes Níveis de Casca de Café ${ }^{1}$
}

\author{
Fernando Salgado Bernardino ${ }^{2}$, Rasmo Garcia ${ }^{3}$, Fernanda Cipriano Rocha ${ }^{2}$, Alexandre Lima de \\ Souza $^{4}$, Odilon Gomes Pereira ${ }^{3}$
}

RESUMO - Foram avaliados os efeitos da adição de 10, 20, 30 e 40\% de casca de café ao capim-elefante, com base na matéria natural, sobre a composição bromatológica, a digestibilidade in vitro da matéria seca (DIVMS) e a produção e composição do efluente resultante do processo de ensilagem. Utilizaram-se 20 silos cilíndricos de PVC com 0,25 m de diâmetro por 0,75 m de altura, distribuídos em delineamento inteiramente casualizado, com quatro repetições. A casca de café foi eficiente na redução da umidade da silagem, estimandose acréscimo de $0,69 \%$ no teor de matéria seca para cada unidade percentual de casca adicionada. Houve redução linear do pH com o aumento dos níveis do aditivo. Verificou-se efeito quadrático da adição de casca de café nos teores de proteína bruta, estimando-se teor máximo de 10,0\% com a adição de 26,3\% de casca. A adição de casca promoveu reduções nos teores de nitrogênio amoniacal, fibra em detergente neutro e na DIVMS e aumentos lineares dos teores de nitrogênio insolúvel em detergente ácido e lignina. Os teores de fibra em detergente ácido e de celulose não foram influenciados pela adição de casca de café. Observou-se produção de efluente apenas nas silagens com 0 e $10 \%$ de casca de café. As concentrações de sólidos totais, P, Na e K do efluente não foram influenciadas pelos dias de coleta. Todavia, registrou-se redução linear da concentração de Mg e aumento da concentração de nitrogênio total. Os valores de demanda biológica de oxigênio e demanda química de oxigênio não foram influenciados pelos dias de coleta. Conclui-se que a adição de $20 \%$ de casca garantiu boa preservação da silagem e eliminou a produção de efluente.

Palavras-chave: aditivo, demanda biológica de oxigênio, ensilagem, pH

\section{Production and Characteristics of Effluent and Bromatological Composition of Elephantgrass with Different Levels of Coffee Hulls Addition}

\begin{abstract}
The experiment was carried out to evaluate the effects of levels (10, 20, 30 and 40\%, based on fresh matter) of coffee hulls added to elephantgrass at ensilage on the bromatological composition, in vitro dry matter digestibility (IVDMD) of the resulting silage and the production and composition of the silo effluent. Twenty cylindrical plastic silos measuring $0.25 \mathrm{~m}$ diameter $\mathrm{x} 0.75 \mathrm{~m}$ height were used. A complete randomized design was used with four replications. The results demonstrated coffee hulls efficiency on decreasing silage moisture, resulting in increase of DM content of $0.69 \%$ / unity of added additive. pH values decreased as levels of coffee hulls increased. The addition of coffee hulls favored the crude protein contents, which showed a quadratic effect, estimating maximum of $10.0 \%$ at $26.3 \%$ of coffee hulls addition. The addition of coffee hulls reduced ammoniacal nitrogen, insoluble neutral detergent fiber and IVDMD, and increased acid detergent insoluble nitrogen and lignin contents. Acid detergent fiber and cellulose contents were not affected. Effluent production during 21 days was reduced from $123.5 \mathrm{~L} / \mathrm{t}$ ( $0.0 \%$ coffee hulls) to $26.7 \mathrm{~L} / \mathrm{t}$ (10.0\% coffee hulls). The dry matter, P, Na and $\mathrm{K}$ contents did not varied with number of days of collect, although the Mg content decreased and total nitrogen content increased. The values of biological oxygen demand and chemical oxygen demand were not affected. The addition of $20 \%$ of coffee hulls was efficient to eliminate effluent production and to produce a good quality silage.
\end{abstract}

Key Words: additive, biological oxygen demand, ensiling, $\mathrm{pH}$

\section{Introdução}

O uso de silagens de gramíneas tropicais tem se tornado muito comum na produção de ruminantes no Brasil, como forma de utilização do excedente da produção forrageira do período chuvoso do ano para minimizar o problema de escassez de alimento no período seco. Entre as gramíneas perenes, o capim- elefante (Pennisetum purpureum Schum.), tradicionalmente utilizado para corte em capineiras, tem se destacado como forrageira para ensilagem. Seu uso é indicado principalmente em razão de suas características de produção de matéria seca e de seu valor nutritivo (Andrade \& Lavezzo, 1998).

Entretanto, no momento ideal para o corte, o capim-elefante e as gramíneas em geral apresentam

\footnotetext{
1 Parte da tese do primeiro autor, projeto parcialmente financiado pela FAPEMIG.

2 Zootecnista, M.Sc, DZO/UFV. E.mail: fsbernardino@gmail.com

3 Professor do DZO/UFV, Bolsista do CNPq.

4 Zootecnista, DS, UFMT.
} 
alto teor de umidade, baixas concentrações de carboidratos solúveis e alta capacidade tampão. Essas características influenciam negativamente o processo fermentativo, impedindo o rápido decréscimo do $\mathrm{pH}$, permitindo a ocorrência de fermentações secundárias indesejáveis e, conseqüentemente, prejudicando a qualidade do produto preservado (McDonald, 1981; Lavezzo, 1993).

A ensilagem de gramíneas com alta umidade favorece as perdas durante as diferentes fases do processo. Identificar as fontes de perda e sua magnitude é importante para maximizar a utilização dessas forrageiras. Segundo McDonald (1981), silagens elaboradas a partir de forrageiras com baixo teor de matéria seca podem propiciar o desenvolvimento de bactérias do gênero Clostridium, que produzem ácido butírico, provocando a degradação de proteína e ácido lático. Conforme o autor, a formação de ácido butírico resulta em grandes perdas de matéria seca, em decorrência da produção de $\mathrm{CO}_{2}$ e $\mathrm{H}_{2} \mathrm{O}$, e de energia. Além disso, quando colhido com alto teor de umidade, significativa proporção de nutrientes do capim-elefante é eliminada pelo efluente (Loures et al., 2003). Portanto, a redução da umidade a partir de técnicas como préemurchecimento e inclusão de aditivos absorventes é necessária para a ensilagem de gramíneas com alto teor de umidade.

A casca de café, resíduo proveniente do beneficiamento do grão, por apresentar elevado teor de matéria seca e boa capacidade de absorção, pode atuar como eficiente aditivo absorvente. Bons resultados têm sido obtidos em pesquisas envolvendo a adição de casca de café durante a ensilagem (Souza et al., 2001; Quadros et al., 2002). Entretanto, nesses estudos, não foram avaliadas as perdas na produção e composição do efluente.

Neste experimento, avaliaram-se as alterações na composição bromatológica da silagem de capim-elefante contendo diferentes níveis de casca de café e a produção e composição do efluente resultante do processo de ensilagem.

\section{Material e Métodos}

O experimento foi conduzido no Departamento de Zootecnia (DZO) da Universidade Federal de Viçosa (UFV), em Viçosa, MG, no período de 23 de novembro de 2001 a 31 de julho de 2002. As análises foram realizadas nos laboratórios de Nutrição Animal (DZO) e de Matéria Orgânica e Resíduos (DPS) da Universidade Federal de Viçosa.

A forrageira utilizada foi o capim-elefante (Pennisetum purpureum Schum.) cultivar Cameroon, proveniente de capineira já estabelecida no Departamento de Zootecnia da UFV, apresentando 12,4\% de matéria seca e aproximadamente $1,80 \mathrm{~m}$ de altura. A área utilizada para o corte do capim, localizada próxima às instalações de um curral de confinamento, apresenta pequena declividade e foi adubada regularmente com esterco. O capim foi cortado manualmente no dia 23 de novembro de 2001 e, logo após o corte, foi picado em partículas de 2 a $5 \mathrm{~cm}$, em máquina forrageira estacionária. A casca de café foi processada em moinho tipo martelo com peneira de $2 \mathrm{~mm}$ e adicionada à forragem recém-picada em cinco níveis de inclusão (0, 10, 20, 30 e 40,0\% com base na atéria natural). A composição bromatológica do capimelefante e da casca de café utilizados para ensilagem encontram-se na Tabela 1.

Para confecção das silagens, foram utilizados silos laboratoriais de PVC, com 0,25 m de diâmetro e3 $0,75 \mathrm{~m}$ altura. Na parte inferior do silo, havia um cano de PVC de 1/2” " de diâmetro, fechado com tampa de rosca, para escoamento e coleta do efluente produzido. Em cada silo, foram colocados $10 \mathrm{~kg}$ da mistura fresca até a altura de $0,37 \mathrm{~m}$, para obtenção de densidade de $550 \mathrm{~kg} / \mathrm{m}^{3}$. Após o enchimento, os silos foram fechados com tampa interna de madeira revestida de plástico, colocada a $0,37 \mathrm{~m}$ de altura, e lacrados com fita adesiva. Durante os primeiros dias, realizou-se diariamente, no período da manhã, a coleta do efluente, por meio da tubulação coletora. Após a medição do volume, o efluente coletado foi armazenado em frascos plásticos com tampa e mantidos em “freezer” para posteriores análises.

Após 250 dias de armazenamento, os silos foram abertos e todo o seu conteúdo foi retirado e colocado sobre uma lona para homogeneização. Em seguida, foram coletadas duas amostras de cada unidade experimental. Uma amostra foi pesada, acondicionada em saco de papel e colocada em estufa de ventilação forçada a $65^{\circ} \mathrm{C}$ por 72 horas. Posteriormente, foi retirada da estufa, deixada à temperatura ambiente por 1 hora, pesada, para determinação da matéria préseca, e processada em moinho tipo "Wiley”, com peneira de malha de $1 \mathrm{~mm}$ e armazenada em vidro com tampa para posteriores análises. A segunda amostra foi utilizada in natura para análise de $\mathrm{pH}$ e 
Tabela 1 - Composição bromatológica do capim-elefante e da casca de café utilizados na ensilagem

Table 1 - Chemical composition of elephantgrass and coffee hulls at ensilage

\begin{tabular}{|c|c|c|}
\hline $\begin{array}{l}\text { Item } \\
\text { Item }\end{array}$ & $\begin{array}{l}\text { Capim-elefante } \\
\text { Elephantgrass }\end{array}$ & $\begin{array}{l}\text { Cascade café } \\
\text { Coffee hulls }\end{array}$ \\
\hline $\begin{array}{l}\text { Matéria seca (\%) } \\
\text { Dry matter (\%) }\end{array}$ & 12,4 & 89,3 \\
\hline $\begin{array}{l}\text { Proteína bruta (\%MS) } \\
\text { Crude protein (\% DM) }\end{array}$ & 9,8 & 8,3 \\
\hline $\begin{array}{l}\text { NIDA (\%NT) } \\
\text { IADN (\%TN) }\end{array}$ & 12,9 & 39,8 \\
\hline $\begin{array}{l}\text { FDN (\%MS) } \\
N D F(\% D M)\end{array}$ & 74,5 & 64,3 \\
\hline $\begin{array}{l}\text { FDA (\%MS) } \\
A D F(\% D M)\end{array}$ & 50,2 & 48,3 \\
\hline $\begin{array}{l}\text { Lignina (\% MS) } \\
\text { Lignin (\% DM) }\end{array}$ & 7,6 & 14,1 \\
\hline $\begin{array}{l}\text { Celulose (\%MS) } \\
\text { Cellulose (\% DM) }\end{array}$ & 38,3 & 33,4 \\
\hline $\begin{array}{l}\mathrm{Ca}(\% \mathrm{MS}) \\
\mathrm{Ca}(\% \mathrm{DM})\end{array}$ & 0,51 & 0,20 \\
\hline $\begin{array}{l}\mathrm{P}(\% \mathrm{MS}) \\
P(\% D M)\end{array}$ & 0,48 & 0,20 \\
\hline $\begin{array}{l}\mathrm{Na}(\% \mathrm{MS}) \\
\mathrm{Na}(\% \mathrm{DM})\end{array}$ & 0,04 & 0,03 \\
\hline $\begin{array}{l}\mathrm{K}(\% \mathrm{MS}) \\
\mathrm{K}(\% \mathrm{DM})\end{array}$ & 3,61 & 2,22 \\
\hline $\begin{array}{l}\mathrm{Mg}(\% \mathrm{MS}) \\
\mathrm{Mg}(\% \mathrm{DM})\end{array}$ & 0,07 & 0,04 \\
\hline $\begin{array}{l}\text { DIVMS (\%) } \\
\text { IVDMD (\%) }\end{array}$ & 62,6 & 47,2 \\
\hline
\end{tabular}

preparo da solução para análise de nitrogênio amoniacal $\left(\mathrm{N}-\mathrm{NH}_{3}\right)$, segundo Bolsen et al. (1992).

Foram determinadas as concentrações de matéria seca (MS), compostos nitrogenados, fibra em detergente neutro (FDN), fibra em detergente ácido (FDA), lignina, celulose e DIVMS, segundo Silva \& Queiroz (2002), e de nitrogênio insolúvel em detergente ácido (NIDA), conforme técnica descrita por Licitra et al. (1996). Do efluente coletado, foram estimados os teores de minerais ( $\mathrm{P}, \mathrm{Mg}, \mathrm{Ca}, \mathrm{Na}, \mathrm{K}$ ), utilizando-se espectofotômetro, e de nitrogênio total (NT), segundo Silva \& Queiroz (2002); a demanda biológica de oxigênio (DBO) e a demanda química de oxigênio (DQO), segundo Silva (1977). Os sólidos totais ou matéria seca do efluente foram determinados após secagem em estufa a $105^{\circ} \mathrm{C}$.

As variáveis da silagem $\left(\mathrm{pH}, \mathrm{N}-\mathrm{NH}_{3}, \mathrm{MS}, \mathrm{PB}\right.$, FDN, FDA, lignina, celulose, NIDA e DIVMS) foram analisadas em delineamento experimental inteiramente casualizado, com quatro repetições. Os dados foram interpretados estatisticamente por meio de análises de variância e regressão. Os modelos foram escolhidos com base no coeficiente de determinação e na significância dos coeficientes de regressão, a 1\% de probabilidade, utilizando-se o teste " $\mathrm{t}$ " de Student. Para as variáveis do efluente - minerais (Ca, P, Na, $\mathrm{K}$ e Mg), demanda biológica de oxigênio (DBO), demanda química de oxigênio (DQO), nitrogênio total e sólidos totais -, avaliou-se apenas o tratamento com $0 \%$ de casca de café, uma vez que, nos demais tratamentos, não houve produção significativa de efluente. Os dias de coleta do efluente (1, 2, 3, 4, 5, 6 e 7) constituíram os tratamentos, que foram analisados em delineamento inteiramente casualizado, com quatro repetições, segundo o mesmo procedimento estatístico adotado para análise da composição da silagem.

As análises estatísticas foram realizadas utilizando-se o programa SAEG (Sistema de Análises Estatística e Genética), desenvolvido pela Universidade Federal de Viçosa (1997).

\section{Resultados e Discussão}

A composição bromatológica das silagens com níveis crescentes de casca de café, suas respectivas equações de regressão e seus coeficientes de determinação são apresentados na Tabela 2. Verificou-se efeito linear $(\mathrm{P}<0,01)$ da adição de casca sobre o teor de matéria seca da silagem, estimando-se que, para cada unidade percentual adicionada, houve acréscimo de $0,69 \%$ no teor de MS. Com a adição de $20 \%$ de casca, estimou-se teor de 25,7\% de MS, superior ao de 25\%, proposto por Andrade (1995) como mínimo para que não ocorram perdas por efluente na ensilagem do capim-elefante.

A casca de café reduziu com eficiência o conteúdo de umidade das silagens, em decorrência de seu alto teor de MS (89,3\%) e de sua boa capacidade de retenção de umidade. De modo semelhante, Ferrari Jr. \& Lavezzo (2001) adicionaram farelo de mandioca na ensilagem do capim-elefante $(18,7 \% \mathrm{MS})$ e verificaram incrementos de aproximadamente $0,45 \%$ da MS da silagem para cada unidade de farelo adicionada.

Com base no percentual de MS da casca e do capim ensilado, estimou-se participação da casca de café no percentual de MS das silagens de 0,0; 44,4; 
Tabela 2 - Composição bromatológica das silagens

Table 2 - Bromatological composition of the silages

\begin{tabular}{|c|c|c|c|c|c|c|}
\hline \multirow[t]{2}{*}{$\begin{array}{l}\text { Item } \\
\text { Item }\end{array}$} & \multicolumn{5}{|c|}{$\begin{array}{c}\text { Nível de casca de café (\%) } \\
\text { Coffee hulls level (\%) }\end{array}$} & \multirow[t]{2}{*}{$\begin{array}{l}\text { Equação de regressão } \\
\text { Regression equations }\end{array}$} \\
\hline & 0 & 10 & 20 & 30 & 40 & \\
\hline $\begin{array}{l}\mathrm{MS}^{1}(\%) \\
D M^{1}(\%)\end{array}$ & 12,6 & 18,0 & 24,9 & 33,0 & 39,9 & $\hat{Y}=11,7848+0,6948 * * C\left(r^{2}=0,99\right)$ \\
\hline $\mathrm{pH}^{1}$ & 5,1 & 4,7 & 4,4 & 4,1 & 4,0 & $\hat{Y}=4,9835-0,0261 * * C\left(r^{2}=0,96\right)$ \\
\hline $\begin{array}{l}\mathrm{PB}^{1}(\% \mathrm{MS}) \\
C P^{1}(\% D M)\end{array}$ & 5,8 & 9,2 & 9,5 & 9,6 & 9,2 & $\hat{\mathrm{Y}}=6,0840+0,3004 * * \mathrm{C}-0,0057 * * \mathrm{C}^{2}\left(\mathrm{R}^{2}=0,85\right)$ \\
\hline $\begin{array}{l}\mathrm{N}-\mathrm{NH}_{3}{ }^{1}(\% \mathrm{NT}) \\
\mathrm{N}-\mathrm{NH}_{3}{ }^{1}(\% T N)\end{array}$ & 28,7 & 12,4 & 5,6 & 2,8 & 1,9 & $\hat{\mathrm{Y}}=24,8943^{* *} 0,9337^{\mathrm{C}}\left(\mathrm{R}^{2}=0,95\right)$ \\
\hline $\begin{array}{l}\mathrm{NIDA}^{1}(\% \mathrm{NT} \\
\text { ADIN }^{1}(\% T N)\end{array}$ & 16,4 & 21,8 & 24,5 & 26,6 & 27,9 & $\hat{\mathrm{Y}}=17,8787+0,2778 * * \mathrm{C}\left(\mathrm{R}^{2}=0,93\right)$ \\
\hline $\begin{array}{l}\mathrm{FDN}^{1}(\% \mathrm{MS}) \\
N^{1} F^{1}(\% D M)\end{array}$ & 74,3 & 73,1 & 67,6 & 66,5 & 66,6 & $\hat{\mathrm{Y}}=74,0394+0,2201 * * \mathrm{C}\left(\mathrm{r}^{2}=0,85\right)$ \\
\hline $\begin{array}{l}\mathrm{FDA}^{1}(\% \mathrm{MS}) \\
A D F^{1}(\% D M)\end{array}$ & 51,6 & 55,7 & 53,4 & 53,6 & 53,6 & \\
\hline $\begin{array}{l}\operatorname{Lignina}^{1}(\% M S) \\
\operatorname{Lignin}^{1}(\% D M)\end{array}$ & 8,4 & 11,1 & 12,7 & 14,1 & 14,0 & $\hat{Y}=9,2599+0,1413^{* *} \mathrm{C}\left(\mathrm{r}^{2}=0,89\right)$ \\
\hline $\begin{array}{l}\text { Celulose }^{1}(\% \mathrm{MS}) \\
\text { Cellulose }^{1}(\% D M)\end{array}$ & 39,6 & 39,1 & 38,8 & 36,5 & 38,3 & \\
\hline $\begin{array}{l}\text { DIVMS (\%) } \\
\text { IVDMD (\%) }\end{array}$ & 57,6 & 50,1 & 47,4 & 49,6 & 45,7 & $\hat{\mathrm{Y}}=54,9219-0,2421^{* *} \mathrm{C}\left(\mathrm{r}^{2}=0,71\right)$ \\
\hline
\end{tabular}

1 Valores observados (observed values).

** Significativo a $1 \%$ de probabilidade pelo teste " $\mathrm{t}$ " (Significant at 1\% of probability by " $\mathrm{t}$ " test).

64,3; 75,5 e 82,8\% da MS total, para os níveis de 0, 10, 20, 30 e 40\% de inclusão de casca na matéria natural, respectivamente.

Os valores de $\mathrm{pH}$ decresceram linearmente com a adição da casca de café. O aumento do teor de MS proporcionou ambiente favorável ao desenvolvimento de bactérias láticas e desfavorável ao desenvolvimento de bactérias do gênero Clostridium, contribuindo para o rápido declínio do $\mathrm{pH}$ e reduzindo o $\mathrm{pH}$ final das silagens. Verificou-se também elevação das concentrações de carboidratos solúveis, pois, segundo Souza et al. (2001), a casca de café apresenta valores em torno de 17,1\%. Esses carboidratos podem ter contribuído para queda do $\mathrm{pH}$, uma vez que são substratos para as bactérias produtoras de ácido lático (McDonald, 1981).

Embora o valor de $\mathrm{pH}$ da silagem não seja considerado isoladamente um bom critério para avaliação das fermentações, pode-se sugerir que as silagens com 20, 30 e 40\% de casca de café apresentaram bom padrão de conservação e valores de $\mathrm{pH}$ final próximos a 4,2.

As silagens obtidas com a adição de casca de café apresentaram maiores teores de $\mathrm{PB}(\mathrm{P}<0,01)$ que aquelas sem casca. A adição de casca de café manteve o valor de PB da silagem próximo ao verificado para o capim-elefante no momento da ensilagem, estimando-se valor máximo de 10,0\% com a adição de 26,3\% de casca de café. O baixo teor de proteína bruta da silagem sem casca de café pode ser atribuído, em parte, à produção de efluente, que contém elevado teor de nitrogênio (Tabela 3), e às reações que ocorrem no material ensilado, que implicam em perda de compostos nitrogenados (Loures et al., 2003). A redução no teor de $\mathrm{PB}$ das silagens com $40 \%$ de casca de café pode ser conseqüência do menor teor protéico da casca em comparação ao capim-elefante, uma vez que essas silagens foram bem preservadas e não houve produção de efluente.

Com a adição da casca de café, o teor de nitrogênio amoniacal $\left(\mathrm{N}-\mathrm{NH}_{3}\right)$ decresceu $(\mathrm{P}<0,01)$ a valores bastante baixos, podendo-se observar comportamento exponencial, com redução acentuada dos valores à medida que se aumentaram os níveis de casca. Essa redução pode ser atribuída à diminuição da atividade de bactérias do gênero Clostridium, que reduzem a proteólise proveniente desses microrganismos (McDonald, 1981). Tosi et al. (1999) encontraram valores de $25 \%$ de $\mathrm{N}-\mathrm{NH}_{3}$ em silagem de capimelefante, de modo semelhante ao observado na silagem 
sem casca de café neste experimento. Pedreira et al. (2001) verificaram redução da quantidade de $\mathrm{N}-\mathrm{NH}_{3}$ ao adicionarem polpa cítrica à silagem de Tifton-85, ao passo que Ferrari Jr. \& Lavezzo (2001) não notaram efeito da adição de até $12 \%$ de farelo de mandioca sobre os valores de nitrogênio amoniacal de silagens de capim-elefante.

Observou-se efeito $(\mathrm{P}<0,01)$ dos níveis de casca de café sobre os teores de nitrogênio insolúvel em detergente ácido (NIDA) das silagens. A adição de casca de café, em razão de seus maiores teores de NIDA (39,8\%) - ocasionados pelo aquecimento durante a secagem e o beneficiamento dos grãos - em relação ao capim-elefante $(12,9 \%)$ no momento da ensilagem, elevou de forma linear os teores de NIDA da silagem.

Os teores de FDN reduziram linearmente $(\mathrm{P}<0,01)$ com a adição de casca de café, possivelmente em razão do menor teor de FDN da casca de café em comparação ao capim-elefante. Com a adição de $40 \%$ de casca, os valores estimados de FDN foram semelhantes ao teor da casca de café, que, nesse nível, contribuiu com aproximadamente 83\% da matéria seca total da silagem.

Os valores de FDA e celulose das silagens (médias de 53,6 e 38,5\%) não foram influenciados pela adição de casca de café. A ausência de alterações nos teores de FDA pode ser justificada pela semelhança entre os valores de FDA do capim ensilado e da casca de café. Esses valores podem ser considerados altos e diminuem o valor nutritivo das silagens. Os resultados obtidos nesse experimento foram mais elevados que os encontrados por Souza et al. (2001), que foram de 46,6; 42,3; 42,5; 41,8 e 44,1, para as silagens de capim-elefante contendo 0,$0 ; 8,7 ; 17,4 ; 26,1$ e $34,8 \%$ de casca de café, respectivamente. Os teores de lignina aumentaram linearmente $(\mathrm{P}<0,01)$ com a adição de casca de café, o que pode ser atribuído ao maior teor de lignina da casca adicionada durante a ensilagem $(14,1 \%)$ em comparação ao do capim (7,6\%). Estimou-se que, para cada unidade percentual de casca adicionada, houve acréscimo de aproximadamente $0,14 \%$ no teor de lignina da silagem obtida.

Observou-se redução linear dos valores de digestibilidade in vitro da matéria seca (DIVMS) quando foram adicionados níveis crescentes de casca de café, estimando-se redução de 0,24\% na DIVMS, para cada unidade percentual de casca adicionada. Embora com maior teor protéico, as silagens com casca de café apresentaram em sua composição elevado teor de lignina, que, provavelmente, contribuiu para redução na sua digestibilidade. Souza et al. (2001) encontraram 64,5\% de DIVMS na silagem de capim-elefante sem casca e declínio de $0,14 \%$ na DIVMS para cada unidade de casca adicionada.

A produção de efluente das silagens em função dos dias de ensilagem é apresentada na Figura 1. Apenas as silagens sem casca de café e com $10 \%$ do aditivo produziram efluente (123,5 e 26,7 L/t, respectivamente). Entretanto, o volume de efluente da silagem com $10 \%$ de casca pode ser considerado insignificante. A inclusão de casca de café em proporções maiores que 20,0\% foi suficiente para eliminar totalmente a produção de efluente. Constata-se, pois, que a casca de café foi eficiente em absorver o excesso de umidade da silagem de capim-elefante, eliminando a produção de efluente. De forma semelhante, Hameleers et al. (1999) concluíram que a polpa de beterraba reduziu a produção de efluente em silagens de milho.

Os valores observados, as respectivas equações de regressão das concentrações de sólidos totais, nitrogênio total, fósforo, potássio, sódio e magnésio e as demandas biológica (DBO) e química de oxigênio (DQO) do efluente da silagem sem casca de café, em relação aos sete primeiros dias de coleta, são apresentados na Tabela 3. Não foi observado efeito ( $\mathrm{P}>0,01)$ dos dias de coleta do efluente para a concentração de sólidos totais, cujos valores médios foram de $25.466,5 \mathrm{mg} / \mathrm{L}$. Os valores registrados na literatura para sólidos totais do efluente são bastante variáveis, com média de 31.730,0 mg/L, encontrada por Loures

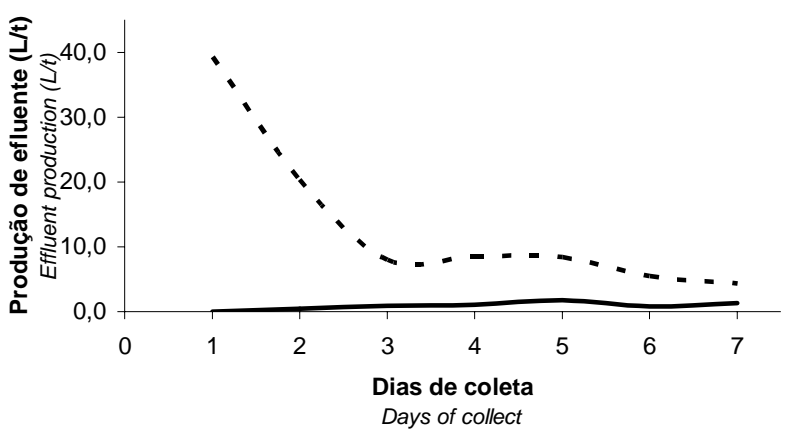

Figura 1 - Produção de efluente observada nos sete primeiros dias de ensilagem do capim-elefante com 0 e $10 \%$ de casca de café.

Figure 1 - Observed effluent production during seven days of ensilage of elephantgrass with 0.0 and $10.0 \%$ of coffee hulls. 
Tabela 3 - Quantidades observadas de sólidos totais, nitrogênio total (NT), minerais ( $P, \mathrm{Na}, \mathrm{K}$ e $\mathrm{Mg}$ ) e demandas biológica (DBO) e química (DQO) de oxigênio do efluente da silagem de capim-elefante sem a adição de casca de café

Table 3 - Observed amounts of total solids, total nitrogen (TN), minerals ( $P, N a, K, M g$ ) and estimated values of biological oxigen requirement $(B O R)$ and chemical oxigen requirement (COR) of elephantgrass effluent without coffee hulls

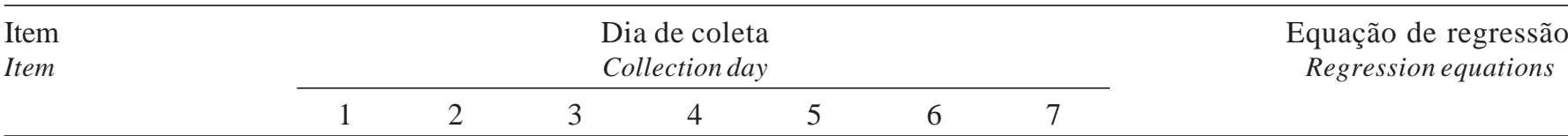

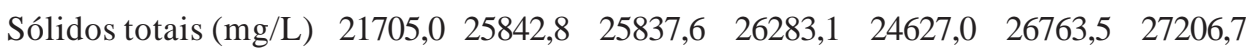

Total solids $(\mathrm{mg} / \mathrm{L})$

$\begin{array}{lcccccccc}\mathrm{NT}(\mathrm{mg} / \mathrm{L}) & 786,7 & 938,4 & 1002,0 & 1051,3 & 1129,0 & 1143,1 & 1171,3 & \hat{\mathrm{Y}}=790,272+6,035 * * \mathrm{D}\left(\mathrm{r}^{2}=0,92\right) \\ \mathrm{TN}(\mathrm{mg} / \mathrm{L}) & 374,6 & 433,5 & 431,8 & 453,4 & 414,5 & 455,7 & 444,4 & \\ \mathrm{P}(\mathrm{mg} / \mathrm{L}) & 13,3 & 13,8 & 14,5 & 13,5 & 13,5 & 13,5 & 13,0 & \\ \mathrm{Na}(\mathrm{mg} / \mathrm{L}) & 3750,0 & 4458,3 & 4437,5 & 4302,8 & 4354,2 & 4504,1 & 4458,3 & \\ \mathrm{~K}(\mathrm{mg} / \mathrm{L}) & 183,7 & 181,5 & 171,1 & 170,5 & 144,9 & 138,7 & 120,3 & \hat{\mathrm{Y}}=201,825-1,079 * * \mathrm{D}\left(\mathrm{r}^{2}=0,93\right) \\ \mathrm{Mg}(\mathrm{mg} / \mathrm{L}) & 19320,0 & 22080,0 & 20355,0 & 21045,0 & 20355,0 & 20010,0 & 20700,0 & \\ \mathrm{DBO}(\mathrm{mg} / \mathrm{L}) & & & & & & & & \\ \text { BOR }(\mathrm{mg} / \mathrm{L}) & 37744,0 & 36288,0 & 38976,0 & 39648,0 & 39144,0 & 37968,0 & 38640,0 & \\ \text { DQO }(\mathrm{mg} / \mathrm{L}) & & & & & & & & \end{array}$

COR $(\mathrm{mg} / \mathrm{L})$

** Significativo a $1 \%$ de probabilidade pelo teste " $\mathrm{t}$ " (Significant at $1 \%$ of probability by " $t$ " test).

et al. (2003) em silagem de capim-elefante, e de 67.000,0 mg/L, observada por Haigh (1999) em silagem de diversas gramíneas de clima temperado.

A análise de variância dos dados de concentração de $\mathrm{P}$, Na e K, em relação aos dias de coleta do efluente, não mostrou diferença $(\mathrm{P}>0,01)$, registrando-se valores médios de 429,7; 13,6; e 4323,6 mg/L, respectivamente. Houve redução linear $(\mathrm{P}<0,01)$ na concentração de Mg, observando-se 1,079 mg/L para cada dia de coleta. Não foi detectada presença de cálcio no efluente, o que, segundo Loures et al. (2003), decorreu da baixa mobilidade deste elemento no tecido da planta.

Obsevou-se efeito dos dias de coleta $(\mathrm{P}<0,01)$ sobre a concentração de nitrogênio total. De acordo com a equação de regressão ajustada, estimaram-se valores de 790,3 mg/L denitrogênio total no primeiro dia e incrementos de $6,035 \mathrm{mg} / \mathrm{L}$ ao passar de cada dia de coleta. Loures et al. (2000) estimaram, para compactação de $550 \mathrm{~kg} / \mathrm{m}^{3}, 682,9 \mathrm{mg} / \mathrm{L}$ para o primeiro dia de coleta, enquanto Haigh (1999) mensurou médias de 1.000 a $5.000 \mathrm{mg} / \mathrm{L}$ de NT de efluente em silagens de gramíneas de clima temperado.

Não houve variação na DBO e DQO com os dias de coleta do efluente, encontrando-se valores de 20.552,1 e 38.344,0 mg/L, respectivamente, que são superiores aos observados por Loures et al. (2003) na ensilagem de capim-elefante e podem ser considerados altos e com grande potencial poluidor. No entanto, os resultados de DBO são inferiores aos valores médios encontrados na literatura, que variam de 40.000 a 90.000 mg/L. A relação DQO/DBO de 1,87 indica que o efluente é facilmente biodegradável, pois, quanto menor a razão DQO/DBO, maior a biodegradabilidade do efluente. As fontes poluidoras devem ser removidas caso haja relação DQO/DBO superior ou igual a 4:1 (Loures et al., 2003).

\section{Conclusões}

A casca de café foi eficiente como aditivo, reduzindo o teor de umidade das silagens de capimelefante e eliminando totalmente a produção de efluente a partir do nível de 20,0\% de inclusão.

A adição de casca de café na ensilagem do capimelefante com $12 \%$ de matéria seca melhorou as características fermentativas da silagem, diminuindo os teores de pH e nitrogênio amoniacal. Entretanto, sua inclusão promoveu acréscimo nos teores de FDN, NIDA e lignina, além de redução da digestibilidade in vitro.

\section{Literatura Citada}

ANDRADE, J.B. Efeito da adição de rolão de milho, farelo de trigo e sacharina na ensilagem do capim-elefante (Pennisetum purpureum Schum.). Botucatu: Universidade Estadual Paulista, 1995. 190p. Tese (Doutorado em Zootecnia) - Universidade Estadual Paulista, 1995.

ANDRADE, J.B.; LAVEZZO, W. Aditivos na ensilagem do capim-elefante. I. Composição bromatológica das forragens e das respectivas silagens. Pesquisa Agropecuária Brasileira, v.33, n.11, p.1859-1872, 1998. 
BOLSEN, K.K.; LIN, C.; BRENT, B.E. et al. Effect of silage additives on the microbial succession and fermentation process of alfalfa and corn silage. Journal of Dairy Science, v.75, n.11, p.3066-3083, 1992.

FERRARI JR., E.; LAVEZZO, W. Qualidade da silagem de capim-elefante (Pennisetum purpureum Schum.) emurchecido ou acrescido de farelo de mandioca. Revista Brasileira de Zootecnia, v.30, n.5, p.1424-1431, 2001.

HAIGH, P. Effluent production from grass silages treated with additives and make in large-scale bunker silos. Grass and Forage Science, v.54, p.208-218, 1999.

HAMELEERS, A.; LEACH, K.A.; OFFER, N.W. et al. The effects of incorporating sugar beet pulp with forage maize at ensiling on silage fermentation and effluent output using drum silos. Grass and Forage Science, v.54, p.322-335, 1999.

LAVEZZO, W. Ensilagem do capim-elefante. In: SIMPÓSIO SOBRE MANEJO DA PASTAGEM, 10., 1993, Piracicaba. Anais... Piracicaba: Fundação de Estudos Agrários “Luis de Queiroz”, 1993. p.169-276.

LICITRA, G.; HERNANDEZ, T.M.; Van SOEST, P.J. Standardization of procedures for nitrogen fractionation of ruminant feeds. Animal Feeding Science and Technology, v.57, n.4, p.347-358, 1996.

LOURES, D.R.S.; GARCIA, R.; PEREIRA, O.G. et al. Características do efluente e composição químico-bromatológica da silagem do capim-elefante sob diferentes níveis de compactação. Revista Brasileira de Zootecnia, v.32, n.6, p.1851-1858, 2003 (supl. 2).

McDONALD, P. The biochemistry of silage. New York: John Wiley \& Sons, 1981. 207p.

PEDREIRA, M.R.; MOREIRA, A.L.; REIS, R.A. et al. Características químicas e fermentativas do Tifton 85 (Cynodon spp.) ensilado com diferentes conteúdos de matéria seca e níveis de polpa cítrica. In: REUNIÃO ANUAL DA SOCIEDADE BRASILEIRA DE ZOOTECNIA, 38., 2001, Piracicaba. Anais... Piracicaba: Sociedade Brasileira de Zootecnia, 2001. CD-ROM.
QUADROS, D.G.; FIGUEIREDO, M.P.; CARDOSO JR., N.S. et al. Perfil dos produtos da fermentação e degradabilidade in situ da matéria seca da silagem de capim-elefante com diferentes percentuais de casca de café. In: REUNIÃO ANUAL DA SOCIEDADE BRASILEIRA DE ZOOTECNIA, 39, 2002, Recife. Anais... Recife: Sociedade Brasileira de Zootecnia, 2002. CD-ROM.

SILVA, D.J.; QUEIROZ, A.C. Análise de alimentos: métodos químicos e biológicos. Viçosa, MG: Universidade Federal de Viçosa, 2002. 235p.

SILVA, M.O.S.A. Análises físico-químicas para controle de estação de tratamento de esgotos. São Paulo: CETESB, 1977. 266p.

SOUZA, A.L.; BERNARDINO, F.S.; GARCIA, R. et al. Valor nutritivo da silagem de capim-elefante (Pennisetum purpureum Schum.) cv. Cameroon com diferentes níveis de casca de café. In: REUNIÃO ANUAL DA SOCIEDADE BRASILEIRA DE ZOOTECNIA, 38., 2001, Piracicaba. Anais... Piracicaba: Sociedade Brasileira de Zootecnia, 2001. CD-ROM.

TOSI, P.; MATTOS, W.R.S.; TOSI, H. et al. Avaliação do capimelefante (Pennisetum purpureum Schum.) cultivar Taiwan A-148, ensilado com diferentes técnicas de redução de umidade. Revista Brasileira de Zootecnia, v.28, n.5, p.947-954, 1999.

UNIVERSIDADE FEDERAL DE VIÇOSA - UFV. SAEG Sistema de análises estatísticas e genéticas. Versão 7.1. Viçosa, MG, 1997. 150p. (Manual do usuário).

Recebido em: 17/03/04

Aceito em: 07/07/05 